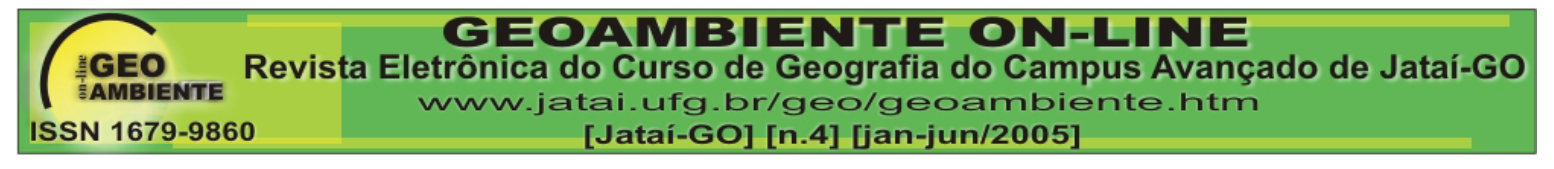

\title{
AS ETAPAS DE ESTRUTURAÇÃO DOS MEIOS DE TRANSPORTE NO BRASIL E O DESENVOLVIMENTO DESIGUAL
}

\author{
Marcos Timóteo Rodrigues de Sousa \\ Pesquisador do Grupo de Estudos Ambientais do UNIFMU e Mestre em Engenharia de \\ Transportes pela UNICAMP (marcossousa@hotmail.com)
}

\section{RESUMO}

Este trabalho tem por objetivo apresentar as etapas de evolução dos meios de transportes no Brasil e entender como se deu o processo de desenvolvimento desigual. Tais problemas surgem com maior intensidade quando se verifica uma grande concentração de infraestrutura na Região Sudeste. A pouca infra-estrutura em outras regiões, aliada a baixa renda da população, ocasionam sérios problemas de integração regional.

Palavras - Chave: estruturação dos transportes, integração regional e políticas públicas.

\section{ABSTRACT \\ THE STAGES OF TRANSPORT WAYS STRUCTURATION IN BRAZIL AND THE UNEQUAL DEVELOPMENT}

This research aim at presenting structure of transport in Brazil, since the colony until actuality, however has serious problems concerning the access to the various regions of the country (uneven development). Such problems come up with more intensity when this is big concentration of the infrastructures in Southeast Region. The low infrastructure of the others regions together the population's low salaries cause serious problems of regional integration.

Key words: transports structure, regional integration and public politics.

\section{Os Primeiros Caminhos}

Todos os caminhos e trilhas encontrados no território brasileiro antes da colonização foram feitos por índios. Basta agora é saber quais eram os objetivos destas trilhas. Talvez pelo instinto da caça, os próprios aproveitavam as trilhas feitas por grandes animais em fuga. Como salienta Silva (1949), os indígenas não possuíam, para abertura de estradas, nem ferramentas, nem conhecimentos técnicos.

Neste grande sistema de viação indígena constata-se que figurava como tronco dessa 


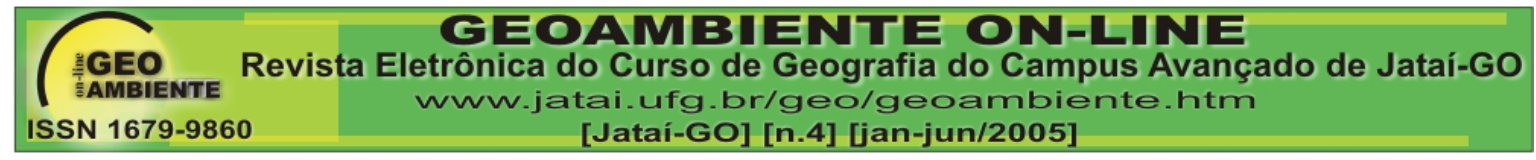

primitiva estrada, uma ligação regional, onde a tribo Guarani da bacia do Paraguai fazia comunicação com as tribos dos Patos no litoral de Santa Catarina, com os Carijós de Iguape e Cananéia e com as tribos de Piratininga e do litoral próximo. Os índios não possuíam veículos e nem animais que os transportassem via terrestre. O cavalo, o boi e o jumento foram introduzidos pelos colonizadores europeus. Nem todas as tribos chegaram a usar madeira para confeccionar embarcações. A distribuição geográfica dos transportes no início do período colonial, estava intimamente ligado aos rumos em que fez o povoamento do país, ou seja, a penetração do território pelo colonizador. Estes colonizadores preferiram logo de início aproveitar os caminhos naturais como trilha de índios, beira de rios, planícies e vegetação rasteira. Os caminhos mais conhecidos no primeiro século de conquista era uma estreita faixa litorânea que ia de São Vicente à Paraíba. Nos séculos XVI e XVII a penetração no interior do Brasil estava reduzida, apenas, ao curso inferior dos rios Paraíba do Sul, Goiana em Pernambuco, numa estrita faixa da zona de produção de cana-de-açúcar e algodão.

Segundo Corrêa (1997) o sistema sesmarial foi o estruturador do território brasileiro, no qual só foi abolido às vésperas da independência. Junto a este modelo houve a ocorrência das bandeiras paulistas, que introduziram a penetração pelo interior do país. O movimento começou na capitania de São Vicente em 1681, onde dois focos de irradiação abriram os caminhos, o primeiro de São Vicente a São Paulo e o segundo de São Vicente a Taubaté, Sorocaba e Itú. Entre 1500 a 1808 as atividades econômicas de transformação eram apenas artesanais, o extrativismo predominava. A colonização do Brasil transformou-o em uma colônia típica de exploração mercantilista, onde se utilizava a economia de plantation.

Outra opção, para os colonizadores, eram as vias fluviais, o circuito pelos rios brasileiros foi importante para a colonização e povoamento. Navegar sobre as águas, em jangadas e canoas, era muito mais fácil, e permitia maior transporte de cargas evitando contato com o sertão. Os primeiros sistemas locais a considerar são aqueles que se formaram em torno das duas baías mais extensas, e de maior importância no litoral, isto é, a Baía de Todos os Santos, abrangendo toda a área do Recôncavo Baiano, e a da Guanabara, centros comerciais. No transporte fluvial, algumas canoas chagavam a levar 440 arrobas de carga, além de munições, armas e mantimentos necessários à viagem, mediam 50 a 60 pés de comprimento por cinco de largura e de três e quatro de fundos. Essas embarcações eram tripuladas por oito homens, que usavam remos e varejões.

Outra boa opção era a via marítima. As ligações entre as capitanias eram feitas por mar 


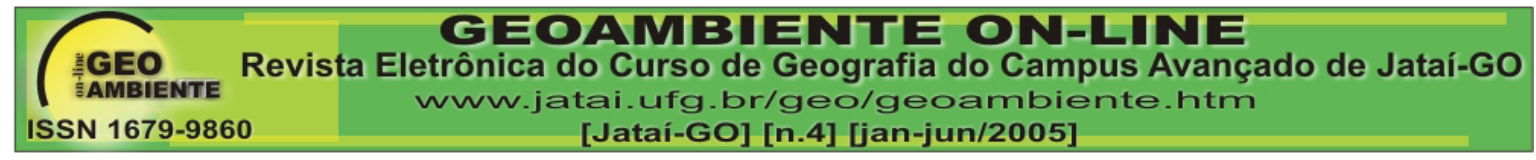

(cabotagem). Havia vários portos. Em alguns portos foram construídas cidades que cresceram de importância de acordo com o desenvolvimento das capitanias e acabaram como centros comerciais de exportação e importação. Os primeiros portos foram: Itamaracá ao Norte e São Vicente ao Sul, estes serviram como delimitação do território nacional em virtude do Tratado de Tordesilhas. As primeiras embarcações do tipo europeu foram construídas no Rio de Janeiro em 1531 sob o comando de Martin Afonso de Sousa (Silva, 1949). Não seriam aplicados capitais para a melhoria das condições da colônia. Por isso não há notícias de providências para construção de vias de interligação e comunicação, e tudo que se fez, inicialmente, no setor, não foi além de exigências no sentido de que fossem abertos caminhos, inseridas nos alvarás de doação de terras (sesmarias / capitanias hereditárias). Os beneficiários pelas sesmarias deveriam construir pontes, viveiros e pedreiras sem o auxílio da Metrópole (Corrêa, 1997).

Silva (1949) diz que no início do século XVIII foram abertas várias estradas ligando o interior brasileiro ao litoral, principalmente em Minas Gerais, para o escoamento da produção de ouro, gado e agrícolas. A técnica viária era, em suma, rudimentar e sumária, e os caminhos muito precários. As primeiras estradas carroçáveis mais ou menos bem lançadas só apareceram depois de 1808, tendo sido construídas no Rio de Janeiro, por iniciativa de Paulo Fernandes, intendente de polícia da corte (estrada Praia Grande Niterói a Maricá - onde D. João viajava de carruagem). O último período colonial, no início do século XIX, com a vinda da família real inicia-se a abertura dos Portos em 28/01/1808 (comércio exterior).

Constata-se que no período colonial não havia diretrizes político-administrativas, para os transportes, entregue à iniciativa privada, com uma modesta participação do setor público. $\mathrm{O}$ descaso da Metrópole constitui-se em lamentável omissão, que perdurou por mais de 300 anos. Um sistema de comunicações e de transportes rudimentar e precário foi à herança do período colonial ao Brasil independente.

\section{Portos e Ferrovias}

A economia do Brasil independente permaneceu agroexportadora, baseada na grande propriedade e no trabalho escravo. Mas, durante toda a primeira metade do século XIX, ela esteve em crise devido à queda das exportações e o aumento desenfreado das importações. Essa crise era expressão de uma recessão mundial que retraía os mercados, agravando os problemas já enfrentados por esses produtos no comércio internacional, tais como o açúcar, tabaco, couro, etc. 


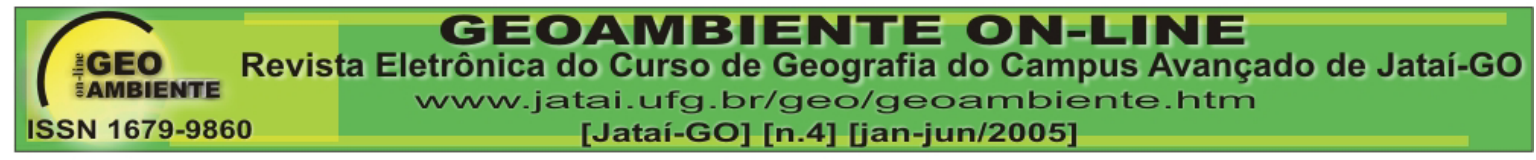

Entre 1830 e 1840, a cafeicultura expandiu-se pelo Sudeste do Brasil e sua produção atendia a $20 \%$ do consumo mundial. Foi aí que houve o desenvolvimento da ferrovia em detrimento das rodovias, para o escoamento mais rápido da produção de café (Coimbra, 1974).

Segundo Barat (1991) em 1831, encontrava-se o país praticamente nas mesmas condições que a Colômbia, no que diz respeito às vias de comunicação e transportes. O país continuava a marchar lentamente, sem forças para superar as dificuldades, que contrapunham à evolução do seu sistema viário. Neste período, foi dada especial atenção ao transporte fluvial e de cabotagem. As estradas foram totalmente esquecidas (1831 a 1840).

O período de 1850 foi de grande progresso econômico com as exportações de café. O transporte como meio de circulação da produção cafeeira seria ampliado. Em 1846, os Portos de Santos e do Rio de Janeiro eram considerados os maiores do país - entreposto de açúcar, aguardente, arroz, café, couros e tecidos. Em 1870, baseados na lei 1746 de 13/10/1869, o Conde da Estrela e o Doutor Andrade Pertence obtiveram a concessão do privilégio de explorar o Porto de Santos por 90 anos e, em 1872, foi aprovado o projeto do engenheiro Breton, que consistia na construção de um caís de 3.000 pés de comprimento ao longo do canal, uma ponta de atracação e uma bacia flutuante para navios calando até 18 pés. Em 1846 os portos de São Luís (MA), exportavam arroz, algodão, aguardente e drogas medicinais. A importância dos portos nacionais, no período que nos ocupa, além de notável, contribuía de maneira decisiva para as finanças do Império. A principal receita era arrecadada em Portos de mar, proveniente dos direitos de importação e exportação. Apesar de toda a importância dos Portos, o governo não o equipava com: quebra-mares, molhes, diques, estaleiros, cais e armazéns e sem segurança, sem iluminação e sinalização, ou seja, 3.660 milhas de litoral não aproveitado (Barat, 1991).

A navegação a vapor inicia-se no Rio Amazonas no ano de 1850 , quem deteve a concessão por trinta anos foi o Visconde de Mauá, com a Companhia de Navegação e Comércio do Amazonas (indústria extrativista).

Segundo Matos (1981) no segundo reinado houve o surto ferroviário, a lavoura cafeeira nos meados do século XIX exigia 50\% da exportação, exigência de uma ligação entre o interior e os portos. Além das exportações de café o país importava vestuário, calçados, gêneros alimentícios, bebidas, ferragens, máquinas e carvão dos Estados Unidos, Inglaterra, Alemanha, Portugal, Espanha e Itália. A lei Euzébio de Queiroz de 04/09/1850 possibilitou o carregamento de capitais nacionais para outras finalidades, que a compra de escravos e a lei 641 de 12/06/1852, 


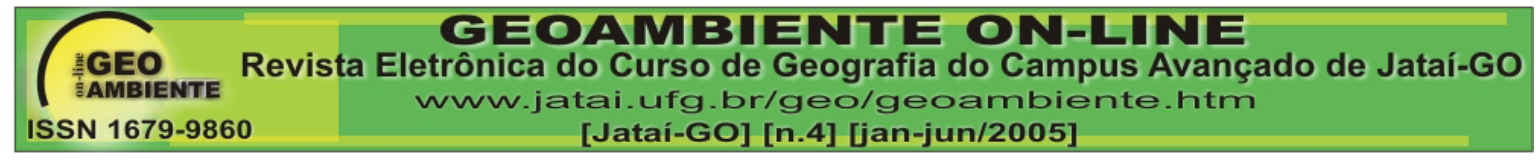

atraia capitais estrangeiros para a construção de estradas de ferro. Até então chegavam ao Porto de Santos cerca de 200.000 mulas carregadas. Para a construção das estradas de ferro foi dada a concessão de 40 a 90 anos, isenção de diretos de importação, doação de terrenos e taxas pelos serviços de transporte privado. $\mathrm{O}$ ano de 1852 marca o ponto de partida da viação férrea no Brasil. Durante o ano de 1873 foram construídos 732.397 quilômetros de linhas férreas nas seguintes estradas: Estrada de Ferro de Petrópolis (Mauá), D. Pedro II, Recife ao São Francisco, Estrada de Ferro Cantagalo (Vila Nova - Friburgo), Santos - Jundiaí, Bahia ao São Francisco, Estrada de Ferro Paulista, Estrada de Ferro Itaúna, Estrada de Ferro Valenciana e Estrada de Ferro Campos - São Sebastião.

Segundo Natal (1991), a Revolução Industrial modificou a economia européia no século XIX, implicando em melhorias, expansão e barateamento dos transportes em nível mundial. A ordem econômica era deixar de lado produtos pesados como madeira e minerais, passando a transportar produtos como café, algodão, borracha e açúcar.

No período Republicano os transportes tinham uma função de escoar a produção agrícola e extrativa somente no sentido litorâneo. A integração do território era apenas no sentido norte/sul e a distribuição dos manufaturados importados ocorria apenas em cidades costeiras. O sistema ferroviário era isolado, visava apenas à ligação dos centros produtores com os portos regionais. A grande quantidade de portos e sistema de navegação de cabotagem permitia uma integração entre os pólos exportadores. As poucas rodovias visavam apenas integração local, atendendo os pequenos centros urbanos. A política de transporte visava uma integração das atividades portuária e ferroviária com a navegação de longo curso, para suprir os países industrializados com insumos e alimentos, com ativos fixos, em grande parte, de propriedade privada externa. Havia ausência de uma política consciente e de coordenação entre os setores produtivos e de transportes, concedendo privilégios e garantia de juros sobre o capital investido na quilometragem construída (Coimbra, 1974).

Em 1889 havia no país 58 linhas férreas. Não obstante, no fim de 1889, havia ainda seis províncias aonde as ferrovias não chegaram: Amazonas, Maranhão, Piauí, Sergipe, Goiás e Mato Grosso. Nota-se também desequilíbrio na distribuição geográfica dos caminhos de ferro: dois terços do total das linhas em tráfego estavam nos territórios das províncias do RJ, MG e SP. A expansão da lavoura cafeeira, nestas três províncias, com constituição de centros de grande importância econômica, determinou o desenvolvimento ferroviário da região. O mesmo 


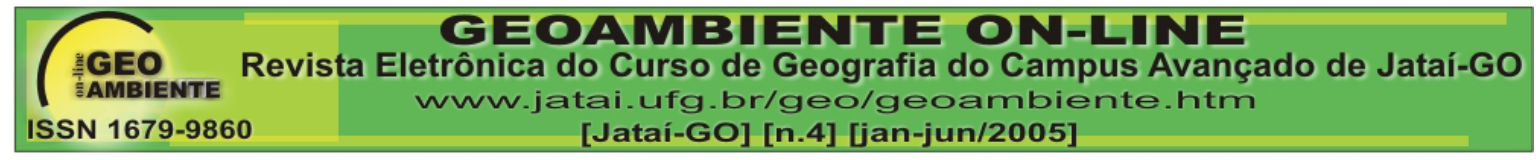

verificou-se no Nordeste porque a cultura canavieira estendia-se na área litorânea, e o transporte de cana, do álcool, e do açúcar industrializado se fazia no dorso de animais ou pela navegação de cabotagem (Barat, 1991).

No início deste período houve poucas melhorias nas estradas de rodagem, houve apenas atenção às estradas de ferro. Para a construção de novas rodovias não houve atração de capitais estrangeiros como aconteceu com as ferrovias. O transporte continuava a ser feito às costas das alimárias e em carros de bois adaptados, até as redes carregadas por homens, nos pequenos trajetos. Apesar deste quadro geral desolador foi construído na segunda metade do século XIX quatros estradas. Referimo-nos a Estrada União e Indústria, entre Petrópolis e Juiz de Fora, à Estrada Dona Francisca, em Santa Catarina, ligando Joinville a São Bento, a Estrada Graciosa, no Paraná, entre Antonina e Curitiba, e, finalmente, a Estrada entre Filadélfia e Santa Clara, em Minas Gerais no escoamento de café (Coimbra, 1974).

As maiores distorções do setor de transportes foram: A) isolamento dos sistemas ferroviários; B) deficiência de traçados das ferrovias; C) decadência dos sistemas portuário e ferroviário com o declínio das exportações, principalmente de café (Matos, 1981).

\section{A Expansão do Sistema Rodoviário}

O pós anos 30 marca um período onde a industrialização se implanta no Brasil com maior impacto devido à desestruturação da oligarquia rural exportadora, com a crise mundial de 1929, e o deslocamento dos capitais do café para as atividades industriais. A Segunda Guerra Mundial, de 1938 a 1945, impediu a importação de produtos europeus, foi outro fator que contribuiu para a industrialização brasileira. O início do período industrial impôs ao sistema de transportes brasileiro uma forte dependência dos setores energéticos (petróleo), automobilístico e construção civil (estradas) (Rodrigues, 2002).

O plano Geral de Viação Nacional, de 29/06/1934, decreto 24.497, foi o primeiro plano oficial do Brasil, nele estipulava-se o seguinte: ligação da Capital Federal (Rio de Janeiro) a uma ou mais capitais dos diferentes Estados; ligassem qualquer via de comunicação da rede federal a qualquer ponto de nossa fronteira com países vizinhos; constituíssem via de transporte ao longo da fronteira, ou dessa paralela, a menos de 200 quilômetros de distância; ligassem entre si dois ou mais trincos de interesse geral, com o objetivo de estabelecer, por caminho mais curto, comunicações entre duas ou mais unidades da federação; atendessem a exigência de ordem 


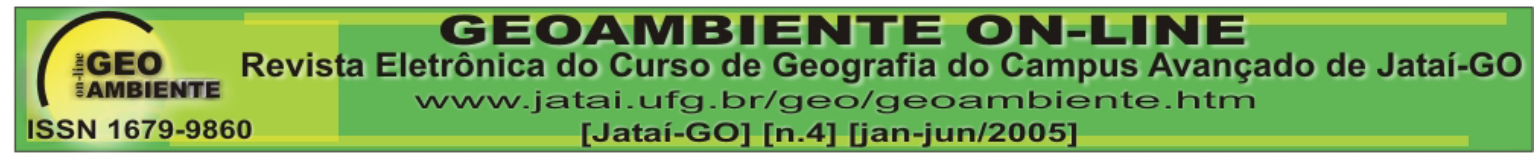

militar.

A dependência, no Brasil, da movimentação de passageiros e cargas ao transporte rodoviário, tem suas origens no período de industrialização pós anos de 1930. Isto se deve à consolidação da urbanização e a integração do mercado industrial ocorridas nas quatro últimas décadas. Assim, o período de maior crescimento industrial (1950-1975) caracterizou-se por considerável ampliação da infra-estrutura rodoviária, tendo em vista seu menor custo de construção por quilômetro, os menores prazos de maturação e retorno dos investimentos e a sua maior adequação ao atendimento dos fluxos de mercadoria territorialmente dispersos (Prado, 1997).

Segundo Natal (1991) a estrutura espacial, altamente polarizada dos mercados de produção consumo, tornou-se responsável pela geração de crescentes volumes de passageiros e cargas, cujo deslocamento passou a ser realizado em corredores rodoviários com elevadas densidades de tráfego. A importância dos corredores de interligação desses grandes mercados nacionais polarizados pode ser observada pela evolução da oferta e das características técnicas da infra-estrutura rodoviária troncal. A princípio estabeleceu-se a interligação pavimentada em pista simples, nos principais trechos das grandes rodovias trocais, como a BR-040, a BR-116 e outras. A BR-116, por promover a interligação Nordeste/Sudeste/Sul do território (permitindo a interligação econômica dos maiores pólos regionais localizados ao longo da faixa litorânea), tornou-se uma das principais vias responsáveis pela ampliação do mercado nacional.

Durante o governo de Juscelino Kubitschek de Oliveira (1956 - 1961), o Brasil atravessou uma fase de grande desenvolvimento industrial, que pode ser justificado pela implantação do primeiro PND (Plano Nacional de Metas), que privilegiava o setor de transportes e energia. Neste período houve uma internacionalização da economia, com a implantação de inúmeras indústrias multinacionais (Volkswagen, Ford e General Motors), e pela participação do governo na economia de base: petróleo, eletricidade, siderurgia e mineração (Lafer, 1975).

Entre os anos de 1956 e 1963 houve uma consolidação das etapas do processo de industrialização. As instalações industriais concentraram-se principalmente na Região Sudeste, entende-se São Paulo, Rio de Janeiro e Belo Horizonte. As maiores contribuições para esta concentração industrial foram: A) as instalações da indústria automobilística; B) expansão da fronteira agrícola com incorporação de novas terras em outras regiões, mas todas dependentes do mercado consumidor do Sudeste, C) consolidação de um mercado interno de âmbito nacional 


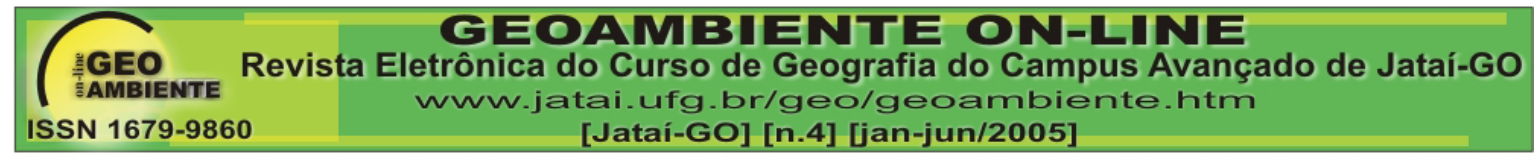

com forte dependência da produção industrial paulista. Nesta fase o setor de transportes expandiu-se buscando ligações com novas fronteiras agrícolas. O sistema de transportes começa a dar sinais de ponto de estrangulamento para a economia nacional. A inflação tem uma alta devido ao déficit operacional cobertos pelo orçamento governamental e dos custos elevados de ineficiência operacional e má distribuição de recursos para investimentos.

Em meados dos anos de 1960 surge uma consolidação do sistema de transporte rodoviário. As rodovias assumem papel preponderante no deslocamento dos fluxos de média e longa distância. O modo ferroviário acentua seu declínio, a navegação de cabotagem torna-se incapaz de atender as necessidades do momento. O mais agravante é a má administração dos órgãos responsáveis. Neste período surge uma intensificação das ligações aéreas entre os grandes centros urbanos do país.

$\mathrm{Na}$ década de 90 dá-se início à recuperação do sistema ferroviário na parte mais desenvolvida do país por meio da concentração de investimentos nos eixos de elevada densidade. Inicia-se um processo modernização portuária e de navegação permitindo a sua adequação às demandas futuras. Estímulos à criação de uma rede aérea de alimentação das linhas tronco para maior incremento do tráfego aéreo. Tudo isto voltado às privatizações dos setores (Prado, 1997).

\section{Desenvolvimento Desigual}

Os investimentos em transportes, atuando como poderoso fator no espaço econômico condiciona novos esquemas de divisão geográfica do trabalho, influenciando a localização de atividades industriais, extrativas, agrícolas e de comércio e serviços. No Brasil, os investimentos são desiguais, portanto geram-se arranjos regionais desiguais. Para iniciarmos esta explanação devemos entender a região, neste momento histórico, como um território apropriado pelo capital, ou seja, um lugar onde há uma seletividade das atividades econômicas. No entanto, as especificidades da economia regional se apresentam desiguais, tornando os lugares diferentes e díspares. Segundo Moreira (1993) a região é por isso então concebida como um todo de síntese única entre as frações de espaço da superfície terrestre e cuja característica básica é a demarcação territorial de limites rigorosamente precisos. Ou seja, como a fração de espaço cuja unidade é dada pela combinação entre uma forma singular de síntese total dos fenômenos físicos e humanos que a compõem e um limite territorial preciso que a diferencia na amplidão da superfície 


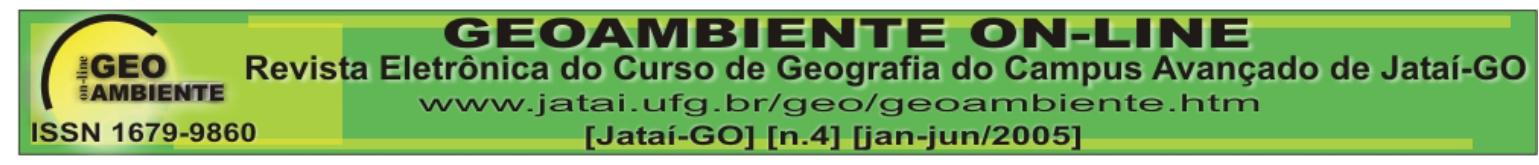

terrestre, a singularidade, justamente, demarcando-a dos demais espaços regionais distribuídos no contexto mais global.

A forte concentração dos equipamentos de transporte na região sudeste causou um desequilíbrio regional ao país. O crescimento desordenado causou problemas no transporte urbano, moradia, segurança e saúde às pessoas. No Brasil até 1964 não existia política habitacional, o Estado não estava preparado para organizar o transporte urbano, havia um forte êxodo rural nos anos 50, 60 e 70, causando inchaço na metrópole paulista e enfraquecimento do trabalho rural. A conurbação ampliou seus horizontes em São Paulo, Rio de Janeiro e Belo Horizonte, criando um forte laço do capital internacional com estas metrópoles do terceiro mundo, formando assim uma economia de aglomeração. Esta aglomeração trouxe demandas comuns por infra-estrutura urbana. Metade da população brasileira está concentrada em apenas 111 municípios e metade da população urbana está em 12 municípios. São Paulo tornou-se uma metrópole global integrada aos grandes circuitos internacionais. A infra-estrutura de transporte não contemplou, de maneira igualitária, todas as regiões brasileiras.

Como afirma Cano (1985) a escola cepalina propôs a substituição de importação, ou seja, uma industrialização na América Latina. Esta colocação da CEPAL vem em forma de crítica à escola néo-clássica francesa e americana da década de 1950. (entre os autores está a crítica à Perroux, dizendo que o mesmo é incapaz de explicar a problemática latino-americana). Esta substituição de importações estava centrada em São Paulo com o aparecimento das indústrias pesadas. A tomada de consciência regional surge em 1951 quando o governo começou a divulgar as contas nacionais iniciadas em 1939, permitindo o confronto entre as regiões. A política industrial brasileira pós 1950 não era apenas marcada pela substituição de importações; era centrada pelo capital estrangeiro e pelo Estado oligopolista.

Dentre os confrontos regionais no Brasil surgiram alguns equívocos. Segundo Cano (1985) havia alguns mitos relatando que o desenvolvimento paulista estava centrado na desgraça de outras regiões e que a industrialização seria a grande solução para as regiões menos favorecidas. Estes mitos resultaram em colocações sobre um suposto imperialismo paulista. Não houve um imperialismo paulista e sim uma forte concentração do capital. O capitalismo é concentrador. Entre os anos de 1919 a 1970 a taxa de crescimento industrial do Brasil foi de $7,0 \%$, enquanto a taxa paulista foi de $8,0 \%$ e a do Nordeste foi de $5,0 \%$ ao ano. 


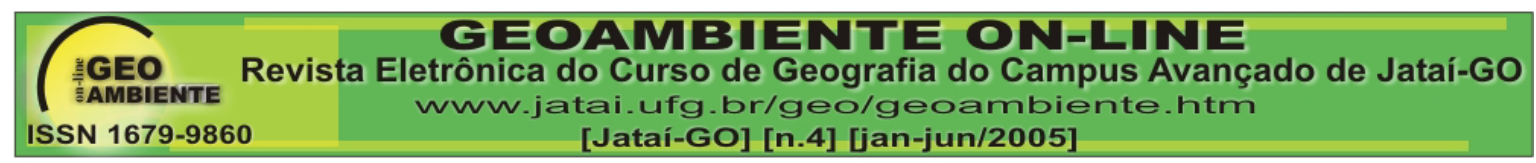

Após os anos de 1970 houve uma mudança da estrutura industrial. Os anos de 1980 foram marcados por uma política de diversificação de exportações. Houve mais créditos rurais e mecanização da agricultura com as produções de soja, trigo, laranja e etc. Geração de demandas derivadas com as novas economias: química, não-ferrosos, metalurgia e leves. Após os anos 80 a desconcentração industrial em São Paulo foi inevitável. A fuga da grande urbanização, impactos ambientais, altos salários, sindicatos e falta de terrenos foram os incentivos para outras regiões. A guerra fiscal por parte dos Estados e Municípios tornou-se um grande atrativo para o capital. Como afirma Negri.

Os anos 90 marcam uma pulverização dos órgãos públicos. O néo-liberalismo desarma o Estado. A participação do capital privado no arranjo territorial do país torna-se mais ativo. Surge uma pequena desconcentração industrial, porém não há uma descentralização. Não há como criar uma política de descentralização se o mercado consumidor está no Sudeste. São Paulo continua centralizando grande parte do poder de decisão econômica do país. No atual momento, o Brasil centraliza um mercado consumidor potencial e um grande poder de decisão econômica num raio de $150 \mathrm{~km}$ da capital paulista. A metrópole com as 39 cidades e mais o Vale do Paraíba, Campinas, Sorocaba e o Litoral são os pólos do capital brasileiro.

Segundo Palhares (2001) o Aeroporto de Guarulhos (SP), movimentou, em 1998, diariamente 120 mil pessoas (visitantes, passageiros, acompanhantes, trabalhadores, prestadores de serviço, etc.) valor que supera a população da maioria dos municípios brasileiros. $\mathrm{O}$ fato mostra que o porte e a geração de tráfego de um aeroporto como de Guarulhos é, em muitas vezes, superior à população da maioria dos municípios do país. Os aeroportos, além de funcionarem como uma das principais infra-estruturas provedoras de acessibilidade entre as sociedades modernas, possuem um papel cada vez mais relevante no desenvolvimento das economias locais, regionais e nacionais.

Para confirmar a concentração de infra-estrutura de transporte em São Paulo comparamos os dados e informações da Fundação SEADE. No ano 2000, o Estado de São Paulo apresentava 196.071 quilômetros de rodovias, somando 14\% de vias pavimentadas, enquanto o Brasil, com 1.724.924 quilômetros de rodovias possuía apenas $9 \%$ de pavimento em estradas $(11,31 \%$ das rodovias estão em São Paulo). O quadro comparativo das ferrovias é seguinte: o Estado de São Paulo possuía 5.419 quilômetros de trilhos e o país detinha 28.056 quilômetros, determinando 19,31\% das ferrovias em São Paulo. O movimento de pousos e decolagens do setor aeroviário 


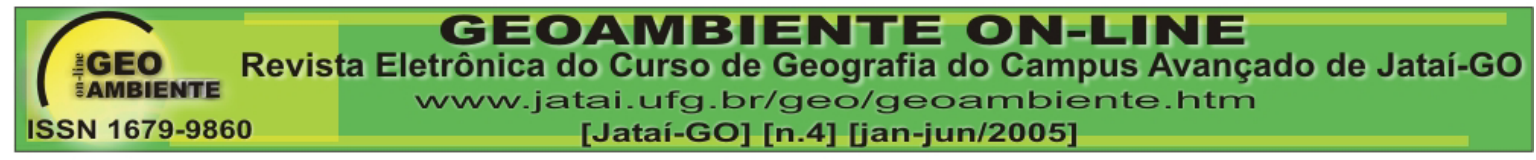

apresentava 568 mil para São Paulo e 2.055 mil para o Brasil, somando 27,64\% do movimento no Estado de São Paulo. O movimento geral de mercadorias no transporte hidroviário apresentava tais números: O país transportou 451.977 mil toneladas, e o Estado de São Paulo movimentou 85.145 mil toneladas, eqüivalendo a 18,845 do movimento geral.

\section{Referências Bibliográficas}

BARAT, J. A evolução dos transportes no Brasil. Rio de Janeiro, IBGE, 1978,385p.

BARAT, J. Transporte e Energia no Brasil. São Paulo: Bertrand, 1991, 143p.

CANO, W. Desequilíbrios Regionais e Concentração Industrial no Brasil. (1930 -1995). Campinas: IE/UNICAMP, 1998, 2. Ed.,289p.

CORRÊA, R.L.(organizador) Explorações Geográficas: percursos no fim do século. Rio de Janeiro: Editora Bertrand, 1997, 367p.

FARIA, S.F.S. Fragmentos da História dos Transportes. São Paulo: Aduaneiras, 2001,96p.

FURTADO, C. Formação Econômica do Brasil. 25 ed. São Paulo: Nacional, 1995,248p.

LAFER, B. M. Planejamento no Brasil. São Paulo, Perspectiva, 1975,187p.

MATOS, O N. Café e ferrovias: a evolução ferroviária de São Paulo e o desenvolvimento da cultura cafeeira. São Paulo: Arquivo do Estado, 1981,227p.

MELO, J. G. Região, cidade e poder. Presidente Prudente, SP: Gasperr, 1996,142p.

MOREIRA, Rua $O$ círculo e a espiral: a crise paradigmática do mundo moderno. Rio de Janeiro: Obra Aberta, 1993,142p.

NATAL, J. L. A. Transporte, ocupação do espaço e desenvolvimento capitalista no Brasil. Campinas: IE/UNICAMP, Tese Doutoral, 1991,392p.

NEGRI, B. Concentração e Desconcentração Industrial em São Paulo.Campinas: IE/UNICAMP, Tese de Doutorado, 1994,367p.

PALHARES, G.L. Transporte Aéreo e Turismo. São Paulo: Aleph, 2001,173p.

PRADO, L. Transportes e Corrupção. Rio de Janeiro: Topbooks, 1997, 475p.

RODRIGUES, P.R.A Introdução aos sistemas de transporte no Brasil e à logística internacional. São Paulo: Aduaneiras, 2002,174p.

SANTOS, M. Estradas Reais. Belo Horizonte: Editora Estrada Real, 2001,179p.

São Paulo. Secretaria de Economia e Planejamento. Fundação Sistema Estadual de Análise de Dados - SEADE. São Paulo em Comparação. São Paulo, 2000, 128p. 


\section{GEOAMBIENTE ON-LINE}

AMBIENTE Revista Eletrônica do Curso de Geografia do Campus Avançado de Jataí-Go ISSN $1679-9860$ [Jataí-GO] [n.4] [jan-jun/2005]

SILVA, M. M. F., Geografia dos transportes no Brasil. Rio de Janeiro: IBGE, 1949, 262p.

SMITH, N. Desenvolvimento Desigual. Rio de Janeiro: Bertrand Brasil, 1988,250p. 